\title{
Inhibitor of Nicotinamide Phosphoribosyltransferase Sensitizes Glioblastoma Cells to Temozolomide via Activating ROS/JNK Signaling Pathway
}

\author{
Jun Feng, Peng-Fei Yan, Hong-yang Zhao, \\ Fang-Cheng Zhang, Wo-Hua Zhao, and Min Feng \\ Department of Neurosurgery, Union Hospital, Tongji Medical College, Huazhong University of Science and Technology, \\ No. 1277 Jiefang Avenue, Wuhan 430022, China
}

Correspondence should be addressed to Min Feng; minfeng07@foxmail.com

Received 6 September 2016; Accepted 10 November 2016

Academic Editor: Steven De Vleeschouwer

Copyright (C) 2016 Jun Feng et al. This is an open access article distributed under the Creative Commons Attribution License, which permits unrestricted use, distribution, and reproduction in any medium, provided the original work is properly cited.

\begin{abstract}
Overcoming temozolomide (TMZ) resistance is a great challenge in glioblastoma (GBM) treatment. Nicotinamide phosphoribosyltransferase (NAMPT) is a rate-limiting enzyme in the biosynthesis of nicotinamide adenine dinucleotide and has a crucial role in cancer cell metabolism. In this study, we investigated whether FK866 and CHS828, two specific NAMPT inhibitors, could sensitize GBM cells to TMZ. Low doses of FK866 and CHS828 (5 nM and $10 \mathrm{nM}$, resp.) alone did not significantly decrease cell viability in U251-MG and T98 GBM cells. However, they significantly increased the antitumor action of TMZ in these cells. In U251-MG cells, administration of NAMPT inhibitors increased the TMZ $(100 \mu \mathrm{M})$-induced apoptosis and LDH release from GBM cells. NAMPT inhibitors remarkably enhanced the activities of caspase-1, caspase-3, and caspase-9. Moreover, NAMPT inhibitors increased reactive oxygen species (ROS) production and superoxide anion level but reduced the SOD activity and total antioxidative capacity in GBM cells. Treatment of NAMPT inhibitors increased phosphorylation of c-Jun and JNK. Administration of JNK inhibitor SP600125 or ROS scavenger tocopherol with TMZ and NAMPT inhibitors substantially attenuated the sensitization of NAMPT inhibitor on TMZ antitumor action. Our data indicate a potential value of NAMPT inhibitors in combined use with TMZ for GBM treatment.
\end{abstract}

\section{Introduction}

Nicotinamide phosphoribosyltransferase (NAMPT) is the rate-limiting enzyme for biosynthesis of nicotinamide adenine dinucleotide $\left(\mathrm{NAD}^{+}\right)$[1]. $\mathrm{NAD}^{+}$is an essential coenzyme involved in cellular redox reactions. Beside, $\mathrm{NAD}^{+}$has been found to be a critical regulator of many pathogeneses such as obesity, diabetes, nonalcoholic fatty liver disease, and insulin resistance [1-6]. More importantly, NAMPT has a crucial role in cancer cell metabolism [7]. NAMPT expression was found to be increased in numerous types of tumors, including colorectal cancer [8], breast cancer [9], gastric cancer [10], ovarian cancer [11], prostate cancer [12]. In these tumors, inhibition of NAMPT had a profound antitumor effect [8-12]. Thus, inhibition of NAMPT by small-molecule chemical compounds such as FK866, CHS828, and STF118804 has emerged to be a promising therapeutic strategy for tumor treatment [13]. Although the antitumor action of NAMPT inhibitor has been widely reported, the effect of NAMPT inhibitor on the sensitivity of other anticancer drugs has not been studied extensively.

Glioblastoma multiforme (GBM) is a devastating glioma with no effective treatment yet. GBMs are mainly composed of star-shaped glial cells known as astrocytes [14-20]. Many parameters, such as promotor methylation and micro-RNAs dysfunction, participate in the genesis and development of GBM [21-27]. Previously, radiotherapy is the standard treatment of GBM. In recent years, combined treatment using radiotherapy plus temozolomide (TMZ) becomes the standard treatment for GBM [28]. TMZ is a DNA-alkylating agent that adds a methyl group to the $\mathrm{O} 6$ position of guanine in genomic DNA to result in tumor cell death [29]. Compared with radiotherapy alone, TMZ addition increased the median survival from 15.3 months to 21.7 months in patients [30]. 
Thus, TMZ is a first-line agent with good efficacy and safety in GBM treatment and may increase survival, especially in patients with methylated MGMT promoter [31]. However, high level of MGMT activity in GBM cells would create a resistant phenotype by blunting the therapeutic effect of TMZ [32]. More importantly, little is known on the acquired TMZ resistance.

The specific higher intracellular expression of NAMPT in GBM was discovered by Reddy et al. in 2008 [33]. Their results also showed that serum extracellular NAMPT levels correlated with tumor grade and was highest in GBM [33]. NAMPT inhibitor FK866 induced C6 glioblastoma cell death via inducing autophagic vacuoles, as well as induced nuclei malformation and mitochondria swelling [34]. Recently, Tateishi et al. reported that NAMPT inhibitor conferred metabolic susceptibility in IDH1 mutant gliomas [35]. The NAMPT inhibitor GMX1778 also enhanced the efficacy of radiolabeled somatostatin analog ${ }^{177} \mathrm{Lu}$-DOTATATE treatment and induces a prolonged antitumor response [36].

In the present study, we hypothesized that NAMPT inhibitor may sensitize glioblastoma cells to TMZ-induced cytotoxic effects. We found that FK866 and CHS828, two distinct NAMPT inhibitors, increased the TMZ-induced apoptosis and necrosis, enhanced the TMZ-induced caspase1 , caspase- 3 , and caspase- 9 activities, and augmented the TMZ-induced oxidative stress in glioblastoma cells. In addition, the activated c-Jun/JNK signaling pathway by NAMPT inhibitors may be involved in the sensitizing action to TMZ.

\section{Materials and Methods}

2.1. Reagents. Assays for reactive oxygen species (ROS), superoxide anion, and SOD activity were purchased from Cell Biolabs Inc. (San Diego, CA). Assays for measuring caspase1 , caspase-3, and caspase- 9 activities were purchased from Beyotime Institute of Biotechnology (Jiangsu, China). Primary antibodies against phospho-JNK, total-JNK, phosphoc-Jun, and total-c-Jun were purchased from Cell Signaling Biotechnology (Danvers, MA). Antibodies against tubulin were purchased from Abcam (Cambridge, UK). The nonradioactive cell viability assay (Cell Counting Kit-8) was purchased from Dojindo Molecular Technologies, Inc. (Kumamoto, Japan). Terminal deoxynucleotidyl transferase dUTP nick end labeling (TUNEL) kit and LDH leakage assay were purchased from Promega (Madison, WI).

2.2. Cell Culture. Human GBM cell lines (U251-MG and T98) were purchased from Cell Bank of Institute of Biochemistry and Cell Biology, Shanghai Institutes for Biological Sciences. Briefly, cells were cultured with Dulbecco's Modified Eagle's medium (DMEM) supplemented with $10 \%$ fetal bovine serum in an incubator with $95 \% \mathrm{O}_{2}$ and $5 \% \mathrm{CO}_{2}$ as described previously [37].

2.3. Cell Viability Assay. Cell viability was evaluated by a nonradioactive CCK-8 kit as described previously [37, 38]. U251-MG and T98 cells $\left(5 \times 10^{3}\right)$ were cultured in 6-well plates and treated with TMZ alone $(25,50,100,200$, and
$400 \mu \mathrm{M}), \operatorname{TMZ}(25,50,100,200$, and $400 \mu \mathrm{M})$ plus FK866 ( $5 \mathrm{nM}$ and $100 \mathrm{nM}$ ), and TMZ plus CHS828 (10 nM and $200 \mathrm{nM})$. At 24 hours after drug treatment, $10 \mu \mathrm{L}$ of CCK-8 solution was added to the culture medium for $1 \mathrm{~h}$ at $37^{\circ} \mathrm{C}$. The absorbing at $450 \mathrm{~nm}$ was recorded by a microplate reader and the relative cell viability was calculated.

2.4. TUNEL Assay. Fluorescent TUNEL staining in glioma cells was conducted as described previously [37]. After 24hour treatment with different drugs, the culture medium was removed. Cells were incubated in TUNEL reaction solution for 2 hours in the dark. Cells were washed with ice-cold PBS solution gently for three times. Then, cells were incubated with DAPI counterstaining solution for $5 \mathrm{~min}$. The DAPI counterstaining solution was discarded and cells were washed by PBS for additional three times. To examine apoptosis, the stained cells were imaged with a fluorescence microscope (IX81, Olympus). The TUNEL-positive cells were thought to be apoptotic cells (green). The total cell number was evaluated by DAPI staining (blue). At least ten visual fields were counted to calculate the proportion of apoptotic cells.

2.5. Lactate Dehydrogenase $(L D H)$ Assay. Cell necrosis was determined with $\mathrm{LDH}$ release using CytoTox-ONE LDH leakage assay as described previously [37]. In brief, the cell culture medium at different time points was transferred to a black fluorescence plate and incubated for 10 minutes with CytoTox-ONE reagent followed by stop solution. Fluorescence was measured at $560 \mathrm{~nm}$.

2.6. Caspase Activity and Oxidant Stress. The activities of caspase-1, caspase-3, and caspase-9 were evaluated with commercial kits according to the manufacturer's instructions. Caspase-1 activity was measured using a specific tetrapeptide substrate Ac-YVAD-pNA. Caspase-3 activity was measured using a specific tetrapeptide substrate Ac-DEVD- $p$ NA. Caspase- 9 activity was measured using a specific tetrapeptide substrate Ac-LEHD- $p$ NA. In these reactions, $p$ NA was generated. The activities of caspase-1, caspase-3, and caspase- 9 were quantified by colorimetric detection of free $p \mathrm{NA}$ at $405 \mathrm{~nm}$.

Four parameters of oxidant stress, including ROS, superoxide anion, total SOD activity, and total antioxidant capacity, were measured using commercial kits from Cell Biolabs Inc. (San Diego, CA) according to the manufacturer's instructions as described previously $[6,37]$.

2.7. Immunoblotting. Immunoblotting assays for phosphorylation of JNK and c-Jun were performed as described previously [37]. Cells were lysed by lysis buffer $(50 \mathrm{mM}$ Tris, $150 \mathrm{mM} \mathrm{NaCl}, 1 \mathrm{mM}$ EDTA, $1 \%$ Triton X, and $\mathrm{pH} 7.4$ ) with protease inhibitors (Pierce, Rockford, IL). After being centrifuged at $12,000 \mathrm{~g}$ for 15 minutes, the supernatant was collected and boiled in $100^{\circ} \mathrm{C}$ with $2 \mathrm{x}$ SDS-PAGE sample loading buffer. Then, the protein samples were run in $10 \%$ SDS-PAGE gel (polyacrylamide 12\%; $100 \mathrm{~V}$ and $30 \mathrm{~mA}$ ). Gels were transferred onto PVDF membranes and processed for immunoblotting with primary antibodies (MGMT, 1:1000; p-JNK, 1:500; JNK, 1:2000; p-c-Jun, 1:500; c-Jun, 1:2000; 
tubulin, 1:1000) and by corresponding IRDye-labeled secondary antibodies. Blots were scanned on Odyssey infrared imaging system (Li-Cor, Lincoln, NE).

2.8. Statistical Analysis. Data are expressed as mean \pm SEM. Differences were evaluated and comparisons between groups were performed by Student's $t$-test or one-way ANOVA with SPSS software (SPSS, Chicago, Illinois). Statistical significance was set at $P<0.05$.

\section{Results}

3.1. NAMPT Inhibitor Sensitizes Glioblastoma Cells to TMZ Treatment. At first, we confirmed the inhibitory effect of NAMPT inhibitor on NAD levels in two human GBM cell lines (U251-MG and T98). MGMT expression was significantly higher in these two cells compared with normal human astrocyte (NHA) cells (Figure 1(a)). As shown in Figure 1(b), both FK866 (5 nM) and CHS828 (10 nM) significantly reduced intracellular NAD levels by $\sim 55-60 \%$. In T98 cells, FK866 (5 nM) and CHS828 (10 nM) inhibited the NAD level by $40-45 \%$ (Figure 1(b)). In U251-MG cells, these two inhibitors alone did not significantly decrease cell viability (Figures 1(c)-1(d)). When the doses of FK866 and CHS828 increased to 100 and $200 \mathrm{nM}$, respectively, the cell viability of U251-MG glioblastoma cells was reduced by FK866 or CHS828 alone (Figures 1(c)-1(d)). In T89 cells, we observed similar phenotypes (Figures 1(e)-1(f)). These data suggest that the low doses of FK866 (5 nM) and CHS828 (10 nM) were noncytotoxic.

In the following experiments, we tested whether $\mathrm{NAD}^{+}$ depletion would modulate the sensitivity of TMZ in glioma cells using FK866 at $5 \mathrm{nM}$ and CHS828 at $10 \mathrm{nM}$. Interestingly, administration of FK866 (5 nM) or CHS828 (10 nM) significantly increased the antitumor action of TMZ in U251-MG and T89 cells (Figures 1(b)-1(f)). Obviously, the combined use of TMZ $(25 \sim 400 \mu \mathrm{M})$ with cytotoxic doses of FK866/CHS828 (100 nM and $200 \mathrm{nM}$, resp.) resulted in more remarkable antitumor effects in these two glioma cell lines (Figures 1(b)-1(f)). All these results indicate that NAMPT inhibitor sensitizes glioblastoma cells to TMZ.

3.2. NAMPT Inhibitor Increases the TMZ-Induced Apoptosis and Necrosis in Glioblastoma Cells. We next measured the effects of NAMPT inhibitor on TMZ-induced apoptosis and necrosis using TUNEL assay and LDH release assay, respectively. In TMZ $(100 \mu \mathrm{M})$ alone treated U251-MG cells, the apoptotic proportion was about $\sim 45 \%$ (Figure 2(a)). In the cell treated with TMZ $(100 \mu \mathrm{M})+$ FK866 $(5 \mathrm{nM})$ or TMZ $(100 \mu \mathrm{M})+$ CHS828 $(10 \mathrm{nM})$, the apoptotic proportion increased to $\sim 75-80 \%$ (Figure $2(\mathrm{a})$ ). LDH assay showed that the LDH contents in culture medium of TMZ + FK866- or $\mathrm{TMZ}+\mathrm{CHS} 828$-treated cells were higher than those in TMZtreated cells (Figures 2(b)-2(c)). These results suggest that NAMPT inhibitor is able to increase TMZ-induced apoptosis and necrosis in glioblastoma cells.

3.3. NAMPT Inhibitor Enhances the TMZ-Induced Caspase1, Caspase-3, and Caspase-9 Activities in Glioblastoma Cells.
We compared the activities of caspase-1, caspase-3, and caspase-9 between TMZ and TMZ + FK866 or TMZ + CHS828 in U251-MG cells. As shown in Figure 3(a), FK866 or CHS 828 enhanced the caspase-1 activity by $\sim 50 \%$. The activity of caspase-3 was also increased by $\sim 100-120 \%$ by FK866 or CHS828 (Figure 3(b)), while the activity of caspase9 was increased 3 -fold by FK866 or CHS828 (Figure 3(c)). These results suggest that NAMPT inhibitor enhances TMZinduced caspase-1, caspase-3, and caspase- 9 activities in glioblastoma cells.

3.4. NAMPT Inhibitor Augments the TMZ-Induced Oxidative Stress in Glioblastoma Cells. Acquisition of chemoresistance in gliomas is associated with decreased oxidative stress [39]. Thus, we assessed the effect of NAMPT inhibitor on the TMZinduced oxidative stress in glioblastoma cells. We found that FK866 or CHS828 significantly increased the TMZ-induced ROS content (Figure 4(a)) and superoxide anion level (Figure 4(b)) in U251-MG cells. Conversely, FK866 or CHS828 reduced the SOD activity (Figure 4(c)) and total antioxidative capacity (Figure 4(d)) in U251-MG glioblastoma cells.

3.5. NAMPT Inhibitor Activates JNK Signaling Pathway in Glioblastoma Cells. The c-Jun/JNK signaling pathway functions in a cell context-specific and cell type-specific manner to integrate signals that affect proliferation, differentiation, survival, and migration in tumor [40]. Immunoblotting assay demonstrated that the levels of phosphorylated JNK and cJun in TMZ + FK866- or TMZ + CHS828-treated U251MG glioblastoma cells were enhanced by $\sim 2$-fold compared with that in TMZ-treated cells (Figures 5(a)-5(c)). These results suggest that NAMPT inhibitor activated JNK signaling pathway in glioblastoma cells.

3.6. JNK Pathway Inhibitor or ROS Scavenger Attenuates the Sensitization of NAMPT Inhibitor on TMZ Antitumor Action in Glioblastoma Cells. Finally we examined effects of c-Jun/JNK pathway inhibitor or ROS scavenger on the sensitization of NAMPT inhibitor on TMZ antitumor action in glioblastoma cells. As shown in Figures 6(a)-6(b), blockade of JNK signaling pathway by SP600125 treatment almost totally abolished the sensitization of NAMPT inhibitor on TMZ antitumor action in U251-MG cells. Moreover, tocopherol, a ROS scavenger, attenuated the sensitization of NAMPT inhibitor on TMZ antitumor action in U251-MG cells (Figures 6(c)-6(d)). These data indicate that both cJun/JNK pathway and oxidative stress are required for the antitumor action of TMZ in glioblastoma cells.

\section{Discussion}

In the present study, we showed the first evidence for the sensitizing action of chemical inhibitors of NAMPT to TMZ treatment in GBM cells. The main findings of this study were as follows: (1) administration of low doses FK866 and CHS828 (5 nM and $10 \mathrm{nM}$, resp.) did not exhibit obvious antitumor action but significantly increased the antitumor action of TMZ in cultured U251-MG and T89 cells; (2) the 


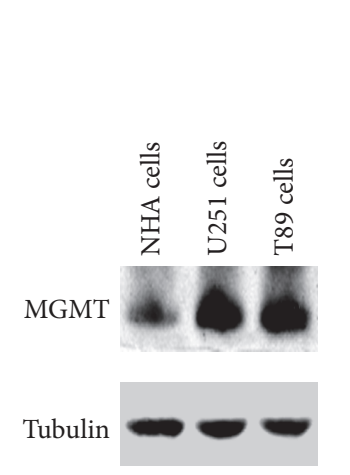

(a)

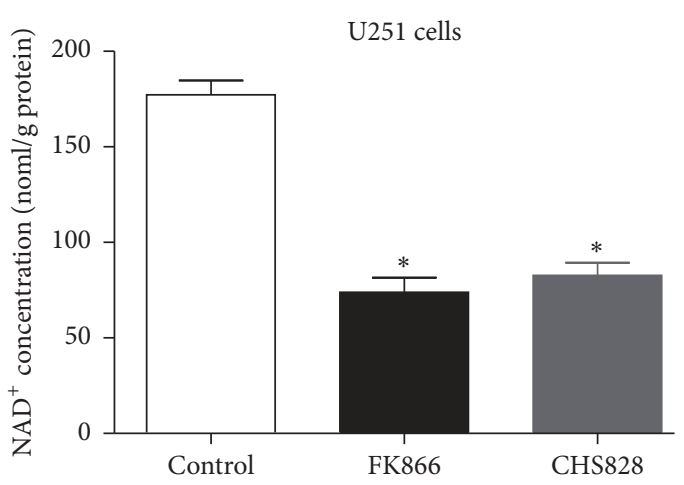

(b)

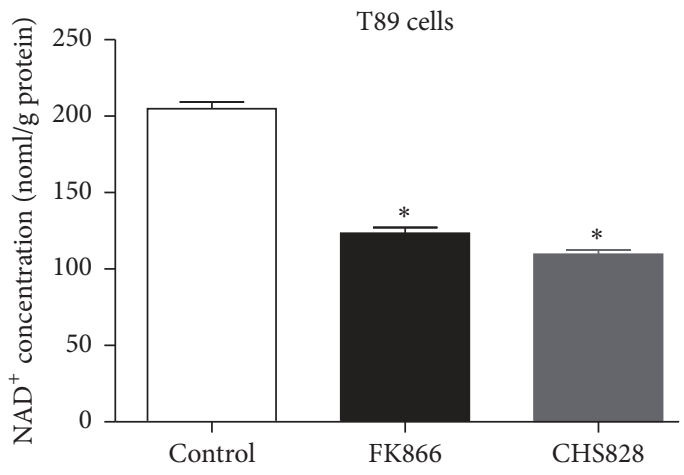

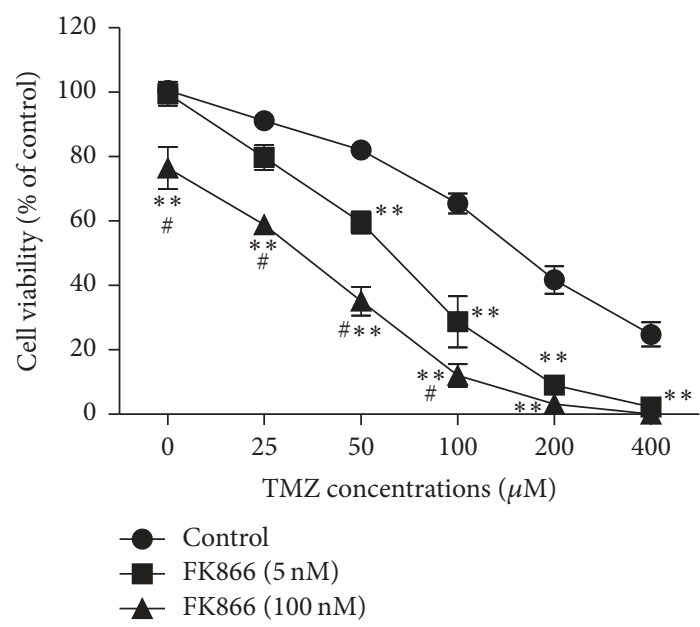

(c)

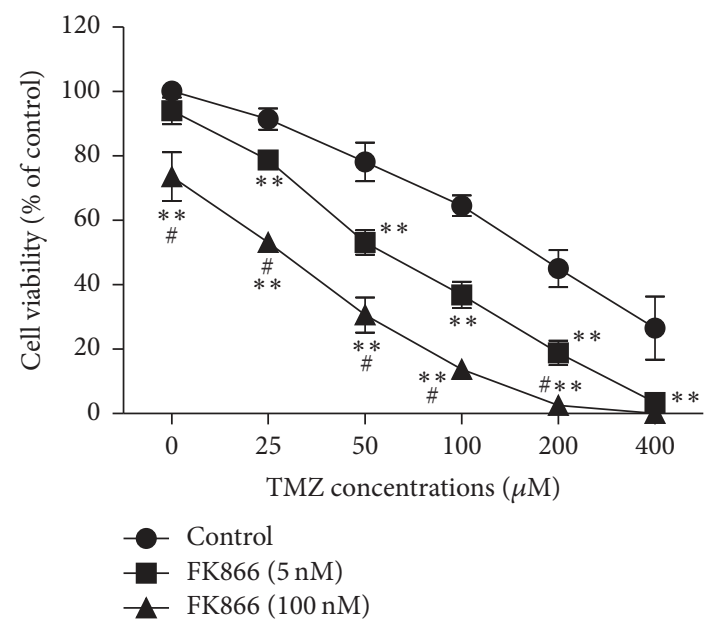

(e)

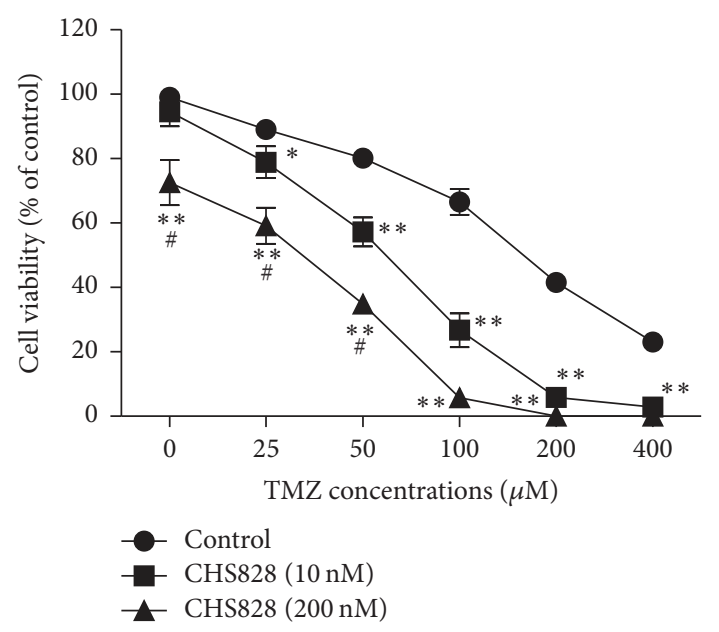

(d)

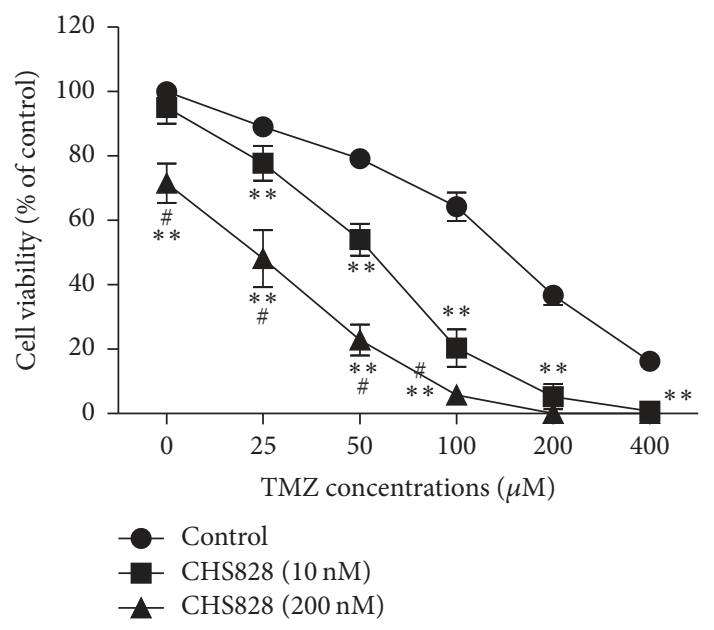

(f)

Figure 1: NAMPT inhibitor sensitizes glioblastoma cells to TMZ treatment. (a) Upregulation of MGMT in U251-MG and T89-MG cells compared with normal human astrocyte (NHA) cells. (b) Confirmation of inhibitory effect of FK866 and CHS828 on NAD concentration in U251-MG and T89-MG cells. (c) Effects of low $(5 \mathrm{nM})$ and high $(100 \mathrm{nM})$ doses of FK866 on cell viability in U251-MG GBM cells. ${ }^{* *} P<0.01$ versus control. ${ }^{\#} P<0.05$ versus FK866 $(5 \mathrm{nM}) . N=8$. (d) Effects of low $(10 \mathrm{nM})$ and high $(200 \mathrm{nM})$ doses of CHS828 on cell viability in U251-MG GBM cells. ${ }^{*} P<0.05$ versus control. ${ }^{*} P<0.05$ versus CHS828 $(10 \mathrm{nM}) . N=8$. (e) Effects of low $(5 \mathrm{nM})$ and high $(100 \mathrm{nM})$ doses of FK866 on cell viability in T89 GBM cells. ${ }^{\#} P<0.05$ versus FK866 $(5 \mathrm{nM}) . N=8$. (f) Effects of low $(10 \mathrm{nM})$ and high $(200 \mathrm{nM}) \mathrm{doses}$ of CHS828 on cell viability in T89 GBM cells. 

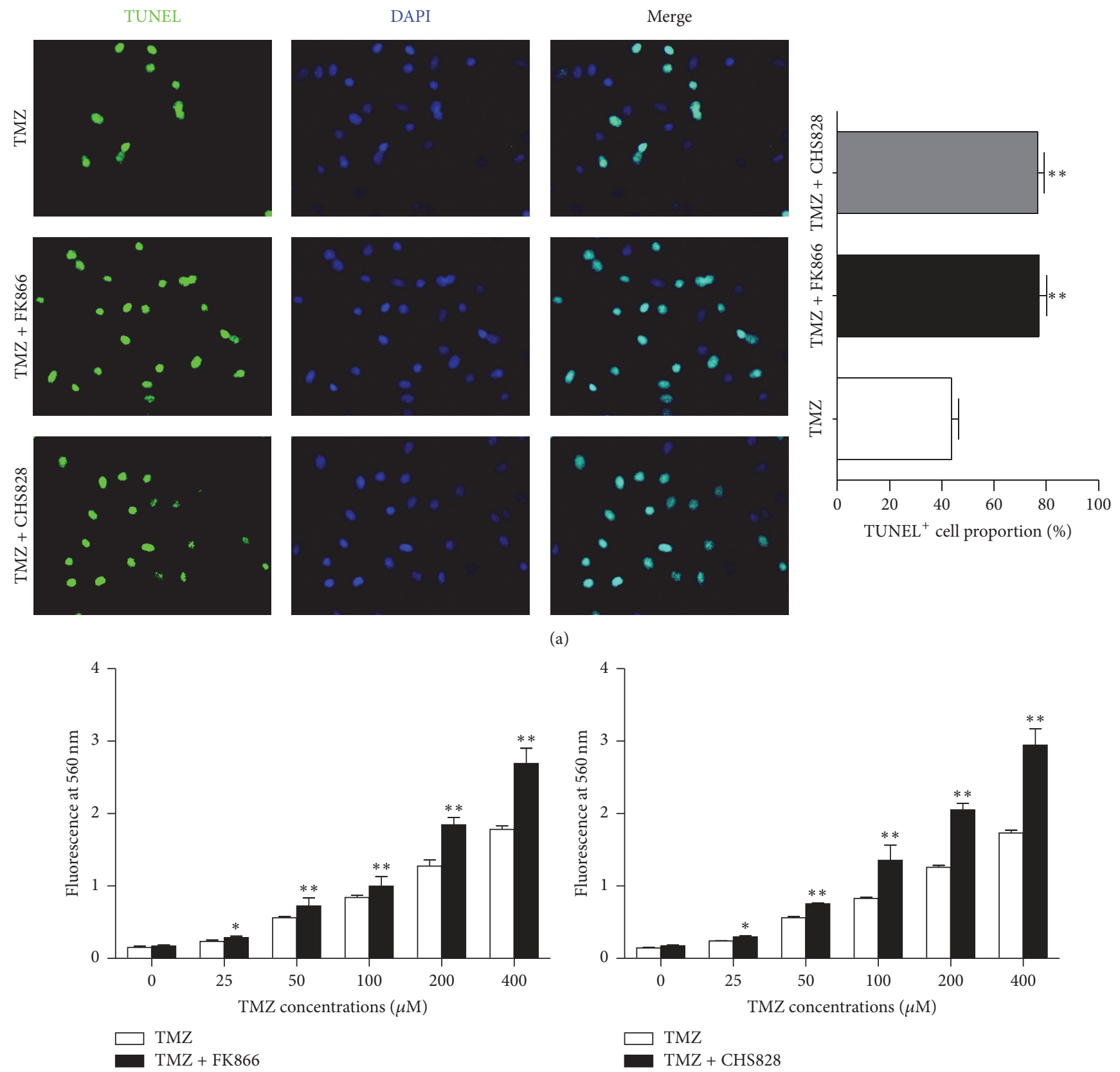

(b)

(c)

FIGURE 2: NAMPT inhibitor increases the TMZ-induced apoptosis and necrosis in glioblastoma cells. (a) Fluorescent images of TUNEL assay and quantitative analysis showing the effect of low doses of FK866 and CHS828 (10 nM and $20 \mathrm{nM}$, resp.) on the apoptosis in U251-MG GBM cells. DAPI was used to stain nuclei. ${ }^{*} P<0.05$ versus TMZ alone. $N=8$. At least 20 visual fields were included for analysis. (b-c) LDH assay showing the LDH content in culture medium of TMZ alone, TMZ plus FK866, and TMZ plus CHS828 treated U251-MG GBM cells. ${ }^{*} P<0.05$ and ${ }^{* *} P<0.01$ versus TMZ alone. $N=8$.

NAMPT inhibitors increased the apoptotic proportion of tumor cells from $\sim 45 \%$ (100 $\mu \mathrm{M}$ TMZ alone) to $\sim 75-80 \%$ and enhanced the $\mathrm{LDH}$ release from cells, which suggested that the cell death was prompted by the supplement of NAMPT inhibitors compared with a single TMZ treatment; (3) the activities of caspases family and the ROS production, which referred the intracellular proapoptotic activity, were further enhanced by NAMPT inhibitors; (4) NAMPT inhibitors activated c-Jun/JNK signaling pathway in U251-MG and T89 cells; and (5) both blockade of JNK signaling pathway by SP600125 treatment and scavenging intracellular ROS by administration of tocopherol successfully reduced the sensitizing effect of NAMPT inhibitors to TMZ in GBM cells. Taken together, these results demonstrate that inhibition of NAMPT sensitizes glioblastoma cells to TMZ via activating ROS/JNK signaling pathway. 


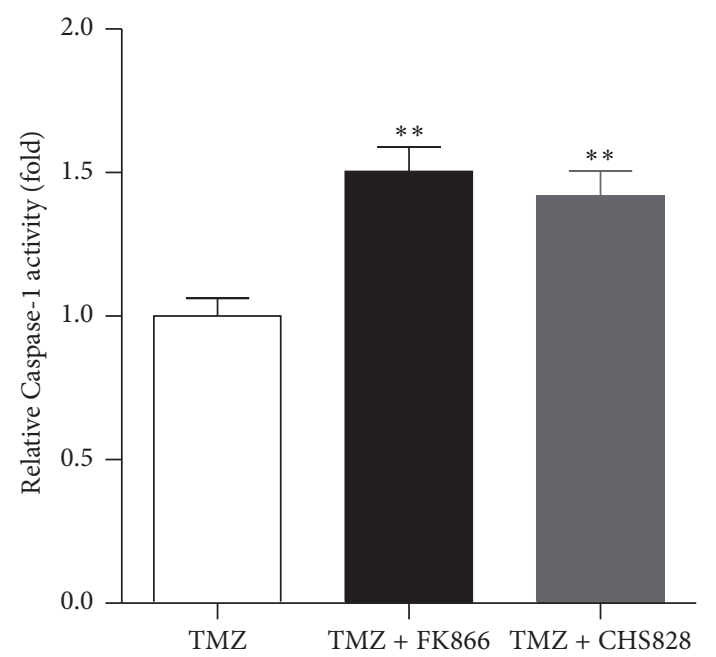

(a)

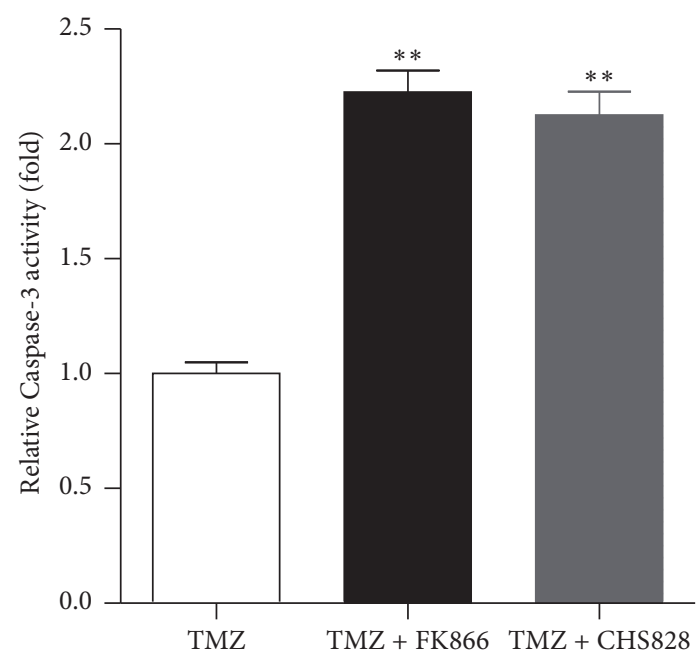

(b)

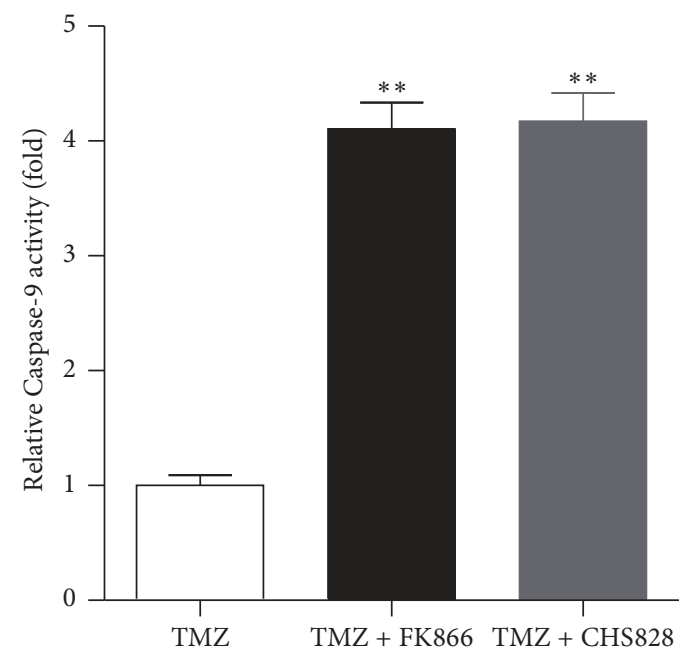

(c)

FIGURE 3: NAMPT inhibitor enhances the caspase-1, caspase-3, and caspase-9 activities in glioblastoma cells. (a-c) Effects of NAMPT inhibitors FK866 and CHS828 on the activities of caspase-1, caspase-3, and caspase-9 in U251-MG GMB cells. ${ }^{* *} P<0.01$ versus TMZ alone. $N=8$.

The interest in NAMPT as an antitumor target comes from the discovery on the involvement and significance of NAMPT as a rate-limiting and most crucial $\mathrm{NAD}^{+}$ biosynthetic enzyme in mammal cells [41]. As tumor cells always have very high intracellular NAD turnover, which is supportive for the increased metabolic demands in rapid proliferation by generating more ATP/energy [42], NAMPT overexpression is rather common in many types of tumor, including leukemia $[43,44]$ and solid tumor [8-12]. Indeed, Zoppoli et al. reported that NAMPT inhibitor FK866 resulted in autophagic cell death in primary B-cell chronic lymphocytic leukemia cells via inducing $\mathrm{NAD}^{+}$depletion, mitochondrial transmembrane potential $\left(\Delta \Psi_{\mathrm{m}}\right)$ dissipation, and ATP shortage [44]. When FK866 was used with tumor necrosis factor-related apoptosis-inducing ligand in leukemia cells, there was a synergistical action in their toxicity towards leukemia cells [44]. Cagnetta et al. confirmed that combined use of FK866 and p-glycoprotein-1 inhibitors showed a strong synergistic cooperative suppression of acute myelogenous leukemia (AML) and B-cell chronic lymphocytic leukemia (B-CLL) sample [43]. In solid tumor, including tumors derived from kidney [45], pancreas [46], lung [47], and breast [48], NAMPT inhibitors have displayed portent anticancer effect.

NAMPT is an important regulator in central nerve system (CNS) biology and CNS disease. A large number of studies have demonstrated that NAMPT participates in the pathophysiological changes of Alzheimer's disease [49, 50], Parkinson's disease [51], cognitive function [52], spinal cord injury $[53,54]$, axons degeneration $[55,56]$, and cerebral ischemic stroke [57-61]. So far, the underlying molecular mechanisms of the action of NAMTP in CNS are not fully understood. It has been speculated most of the functions of NAMPT are attributed to its NAD biosynthesis activity. Specifically, NAMPT protein expression was upregulated in brain malignant $[62,63]$. Thus, NAMPT was thought to be 


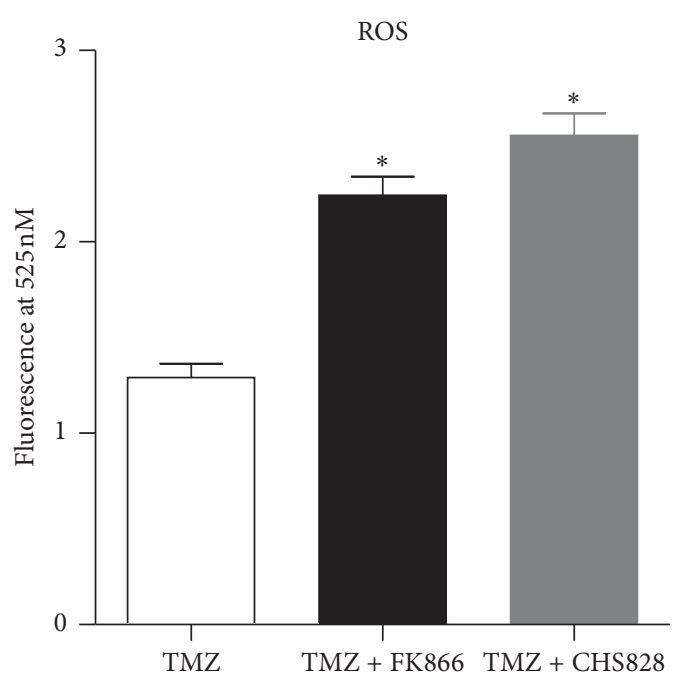

(a)

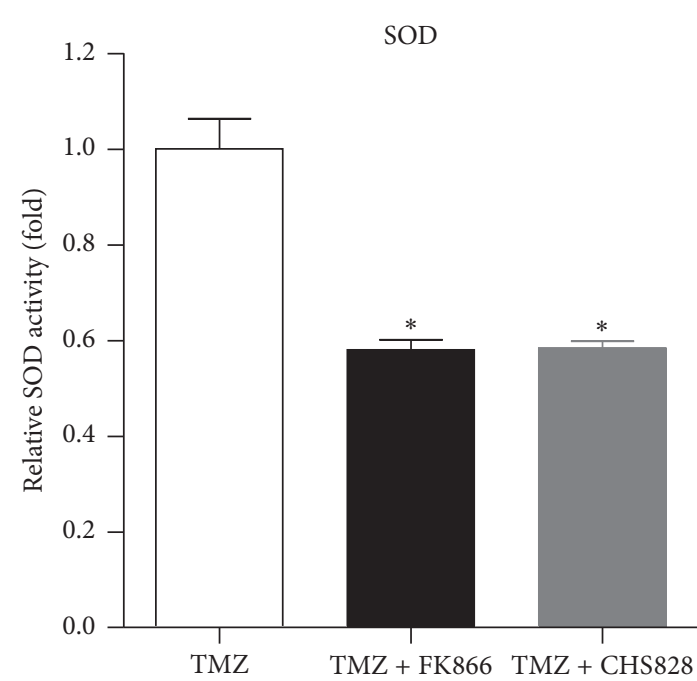

(c)

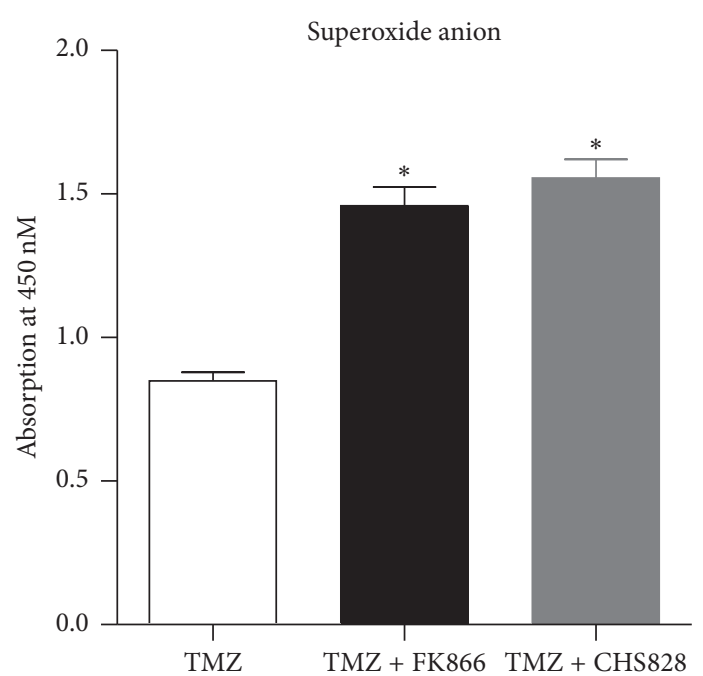

(b)

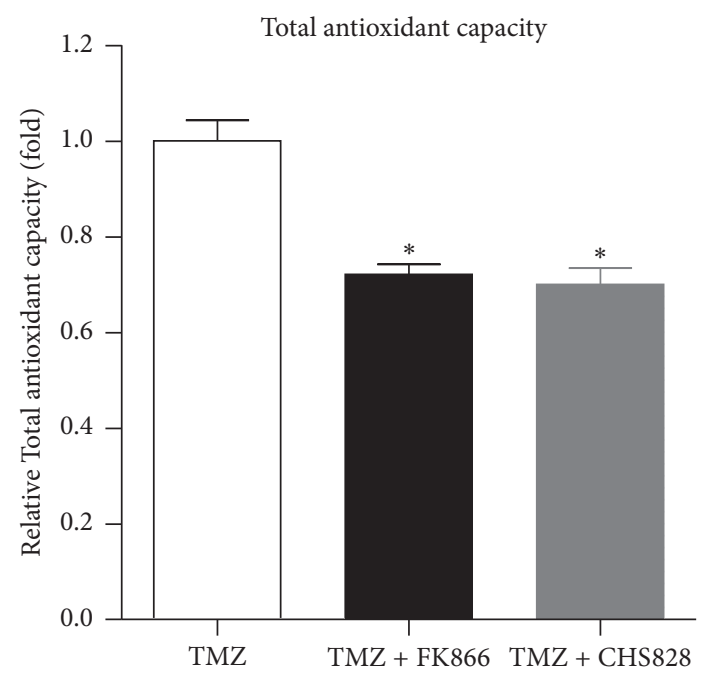

(d)

FIGURE 4: NAMPT inhibitor augments the TMZ-induced ROS production in glioblastoma cells. Relative ROS level (a), superoxide anion level (b), total SOD activity (c), and total-oxidant capacity (d) in U251-MG glioma cells. ${ }^{*} P<0.05$ versus TMZ alone. $N=8$.

a good target for GBM treatment. In our study, we found that NAMPT inhibitor FK866 and CHS828 at very low concentration ( $5 \mathrm{nM}$ and $10 \mathrm{nM}$, resp.) substantially sensitized two human GBM cells to TMZ treatment. It should be noted that NAMPT inhibitor FK866 (5 nM) or CHS828 (10 nM) alone did not significantly decrease cell viability in our study. Previously, Zhang et al. have showed that FK866 could decrease cell viability of three human-derived glioblastoma cells with IC50 about $25 \mathrm{nM}$ [63]. Similarly, the IC50 of CHS828 in HepG2 hepatocellular carcinoma cells is $\sim 25 \mathrm{nM}$ [42]. In line with these results, our data suggest that although FK866 and CHS828 at very low concentration (5 nM and $10 \mathrm{nM}$, resp.) are unable to directly induce cell death in GBM cells, they can cause some intracellular dysfunction in these cells which would render the GBM cells more sensitive to TMZ.

In the following mechanistic analyses, we found that FK866 and CHS828 remarkably enhanced ROS production and activated JNK signaling pathway in GBM cells, because the acquisition of chemoresistance in gliomas to TMZ was shown to be associated with decreased ROS production [39]. Recently, Liu et al. demonstrated that evodiamine, a plant alkaloid, induces JNK-mediated autophagy and calcium/mitochondria-mediated apoptosis in human glioblastoma cells [64]. Also, copper compound was found to induce autophagy and apoptosis of glioma cells by reactive oxygen species and activation of JNK signaling pathway [65]. More importantly, JNK activation is a feature of the late proapoptotic response of glioma cells treated with TMZ [66]. Thus, the increases of ROS level and activated JNK activation by FK866 and CHS828 naturally sensitize glioblastoma cells to TMZ. This is the first work to show the activation of JNK signaling pathway by NAMPT inhibitor in tumor cells.

In conclusion, our results demonstrate that specific chemical inhibitors targeting NAMPT sensitize GBM cells to TMZ treatment, evidenced by their synergistic actions on the cell 


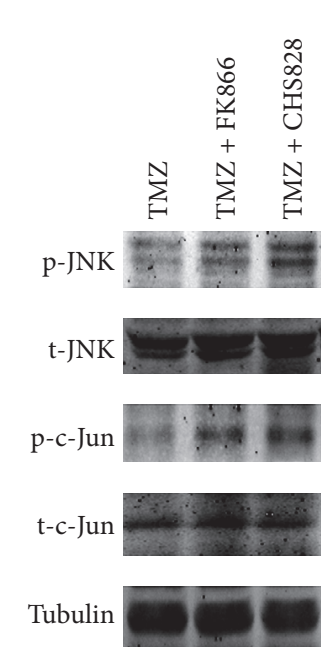

(a)

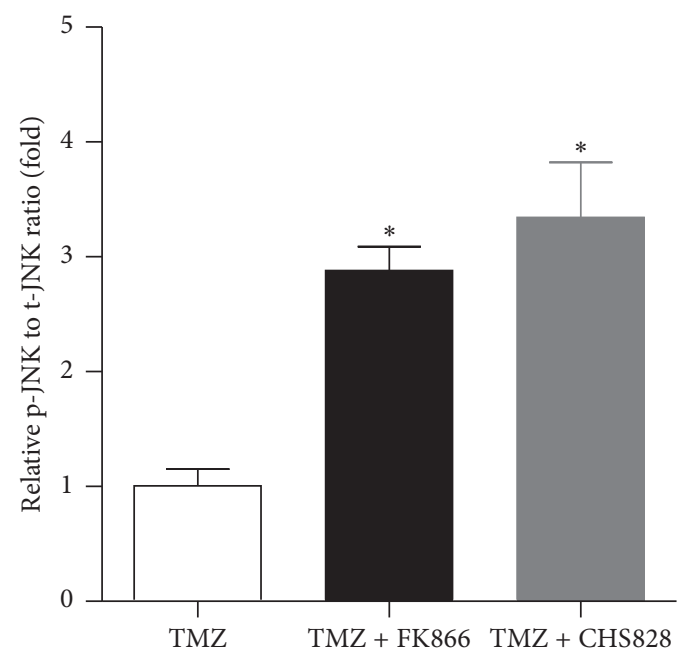

(b)

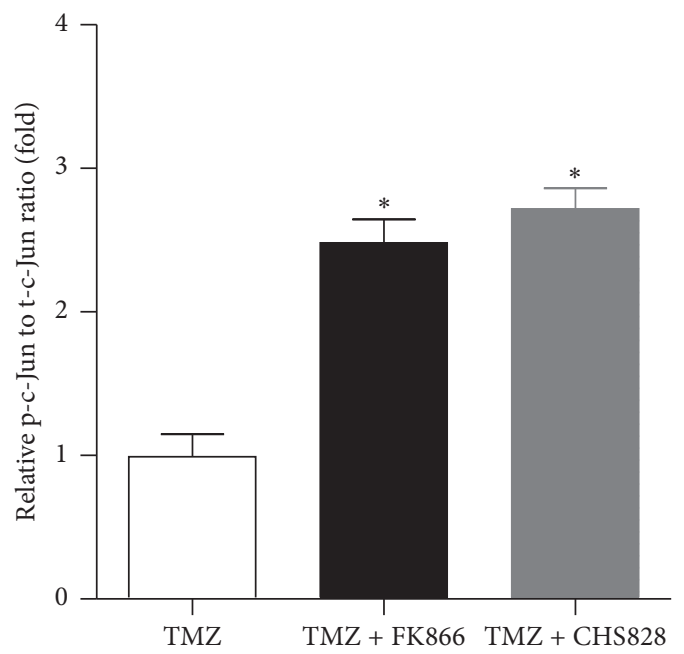

FIGURE 5: NAMPT inhibitor activates c-Jun/JNK signaling pathway in glioblastoma cells. (a) Representative images of phosphorylation of c-Jun and JNK in TMZ alone, TMZ plus FK866, and TMZ plus CHS828 treated U251-MG GBM cells. (b-c) Quantitative analysis on the phosphorylation of c-Jun and JNK in TMZ alone, TMZ plus FK866, and TMZ plus CHS828 treated U251-MG GBM cells. ${ }^{*} P<0.05$ versus TMZ alone. $N=5$.

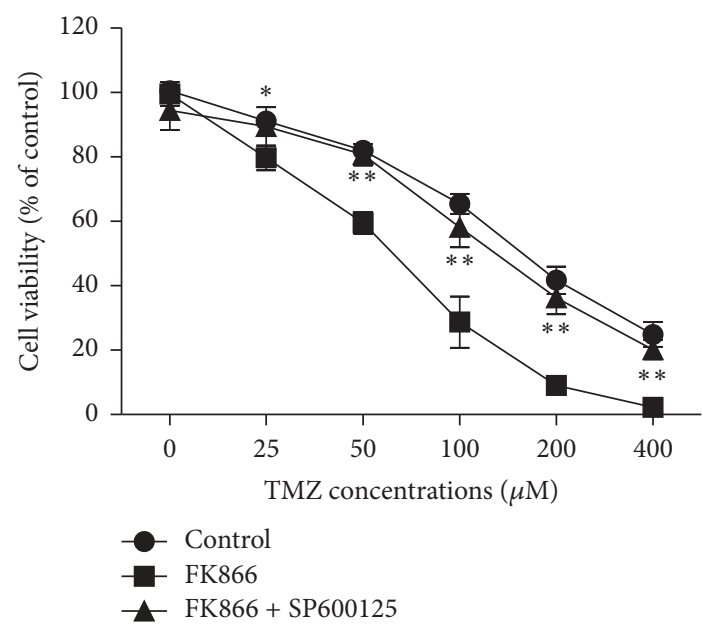

(a)

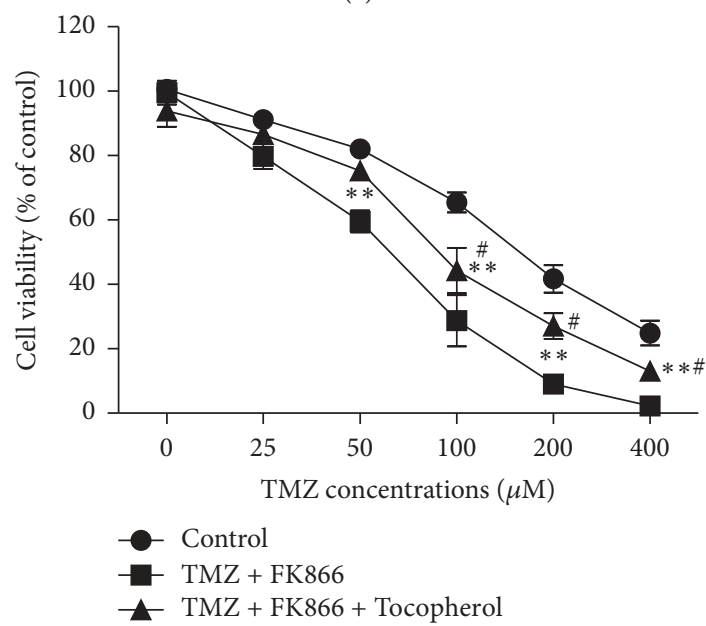

(c)

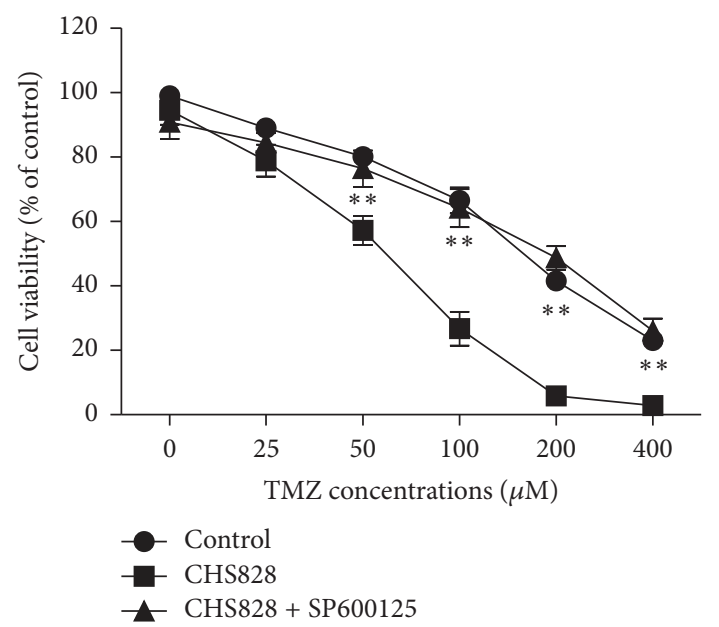

(b)

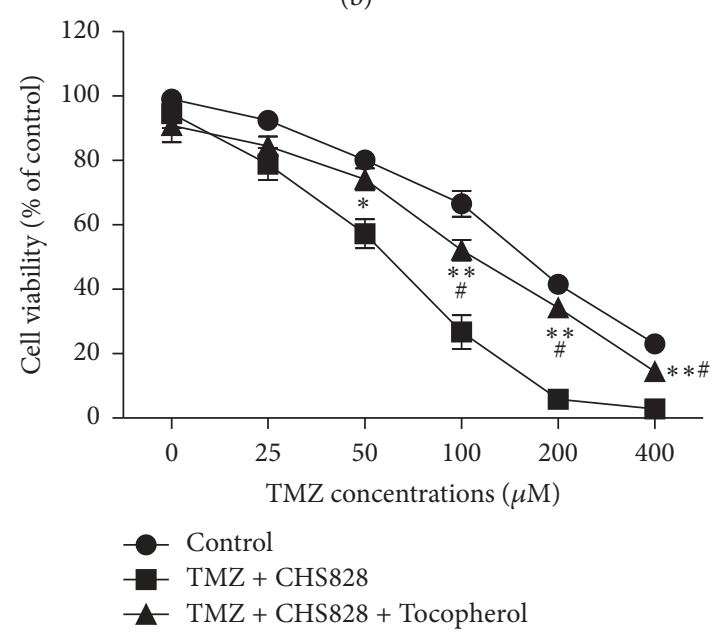

(d)

FIGURE 6: The c-Jun/JNK pathway and ROS production contribute to the sensitization of NAMPT inhibitor on TMZ antitumor action in glioblastoma cells. (a-b) Effects of SP600125, a specific inhibitor of JNK pathway, on the antitumor action of FK866 (a) and CHS828 (b). ${ }^{*} P<0.05$ versus FK866 $(5 \mathrm{nM})$ or CHS828 $(10 \mathrm{nM}) . N=8$. (c-d) Effects of tocopherol, a ROS scavenger, on the antitumor action of FK866 (c) and CHS828 (d). ${ }^{*} P<0.05$ versus FK866 $(5 \mathrm{nM})$ or CHS828 $(10 \mathrm{nM}) . N=8 .{ }^{\#} P<0.05$ versus control. ${ }^{* *} P<0.01$ versus FK866 (5 nM) or CHS828 $(10 \mathrm{nM})$ alone. 
viability, cell death, and apoptotic enzymes activity (caspase family). These phenotypes may be achieved by the enhanced ROS production and activated c-Jun-JNK signaling pathway. These results suggest that NAMPT inhibitors as a sensitizer might be a candidate agent for patients with GBM.

\section{Competing Interests}

The authors declare no competing interests.

\section{Acknowledgments}

This work was supported by the grants from Hubei Province Natural Science Foundation, China (no. 2013CFB127).

\section{References}

[1] A. Garten, S. Schuster, M. Penke, T. Gorski, T. de Giorgis, and W. Kiess, "Physiological and pathophysiological roles of NAMPT and NAD metabolism," Nature Reviews Endocrinology, vol. 11, no. 9, pp. 535-546, 2015.

[2] C. C. Zhou, X. Yang, X. Hua, J. Liu, M. B. Fan, and G. Q. $\mathrm{Li}$, "Hepatic $\mathrm{NAD}(+)$ deficiency as a therapeutic target for non-alcoholic fatty liver disease in ageing," British Journal of Pharmacology, vol. 173, pp. 2352-2368, 2016.

[3] M. J. Yoon, M. Yoshida, S. Johnson et al., "SIRT1-mediated eNAMPT secretion from adipose tissue regulates hypothalamic $\mathrm{NAD}^{+}$and function in mice," Cell Metabolism, vol. 21, no. 5, pp. 706-717, 2015.

[4] J. R. Revollo, A. Körner, K. F. Mills et al., "Nampt/PBEF/Visfatin regulates insulin secretion in $\beta$ cells as a systemic NAD biosynthetic enzyme," Cell Metabolism, vol. 6, no. 5, pp. 363375, 2007.

[5] P. Wang, X. Yang, Z. Zhang et al., "Depletion of NAD pool contributes to impairment of endothelial progenitor cell mobilization in diabetes," Metabolism, vol. 65, no. 6, pp. 852-862, 2016.

[6] J. Song, S.-F. Ke, C.-C. Zhou et al., "Nicotinamide phosphoribosyltransferase is required for the calorie restriction-mediated improvements in oxidative stress, mitochondrial biogenesis, and metabolic adaptation," Journals of Gerontology-Series A Biological Sciences and Medical Sciences, vol. 69, no. 1, pp. 4457, 2014.

[7] A. Garten, S. Petzold, A. Körner, S.-I. Imai, and W. Kiess, "Nampt: linking NAD biology, metabolism and cancer," Trends in Endocrinology and Metabolism, vol. 20, no. 3, pp. 130-138, 2009.

[8] S. E. Hufton, P. T. Moerkerk, R. Brandwijk, A. P. De Bruïne, J.W. Arends, and H. R. Hoogenboom, "A profile of differentially expressed genes in primary colorectal cancer using suppression subtractive hybridization," FEBS Letters, vol. 463, no. 1-2, pp. 7782, 1999.

[9] Y.-C. Lee, Y.-H. Yang, J.-H. Su, H.-L. Chang, M.-F. Hou, and S.-S. F. Yuan, "High visfatin expression in breast cancer tissue is associated with poor survival," Cancer Epidemiology Biomarkers and Prevention, vol. 20, no. 9, pp. 1892-1901, 2011.

[10] T.-Q. Bi, X.-M. Che, X.-H. Liao et al., "Overexpression of Nampt in gastric cancer and chemopotentiating effects of the Nampt inhibitor FK866 in combination with fluorouracil," Oncology Reports, vol. 26, no. 5, pp. 1251-1257, 2011.
[11] R. E. Shackelford, M. M. Bui, D. Coppola, and A. Hakam, "Overexpression of nicotinamide phosphoribosyltransferase in ovarian cancers," International Journal of Clinical and Experimental Pathology, vol. 3, no. 5, pp. 522-527, 2010.

[12] B. Wang, M. K. Hasan, E. Alvarado, H. Yuan, H. Wu, and W. Y. Chen, "NAMPT overexpression in prostate cancer and its contribution to tumor cell survival and stress response," Oncogene, vol. 30, no. 8, pp. 907-921, 2011.

[13] D. Sampath, T. S. Zabka, D. L. Misner, T. O’Brien, and P. S. Dragovich, "Inhibition of nicotinamide phosphoribosyltransferase (NAMPT) as a therapeutic strategy in cancer," Pharmacology \& Therapeutics, vol. 151, pp. 16-31, 2015.

[14] A. Verkhratsky, L. Steardo, V. Parpura, and V. Montana, “Translational potential of astrocytes in brain disorders," Progress in Neurobiology, vol. 144, pp. 188-205, 2016.

[15] S. Nicolaidis, "Biomarkers of glioblastoma multiforme," Metabolism: Clinical and Experimental, vol. 64, no. 3, pp. S22-S27, 2015.

[16] B. D. Arbo, F. Benetti, and M. F. Ribeiro, "Astrocytes as a target for neuroprotection: modulation by progesterone and dehydroepiandrosterone," Progress in Neurobiology, vol. 144, pp. 27-47, 2016.

[17] A. R. Filous and J. Silver, "Targeting astrocytes in CNS injury and disease: a translational research approach," Progress in Neurobiology, vol. 144, pp. 173-187, 2016.

[18] S. Hostenbach, M. D'haeseleer, R. Kooijman, and J. De Keyser, "The pathophysiological role of astrocytic endothelin1," Progress in Neurobiology, vol. 144, pp. 88-102, 2016.

[19] M. Pulido-Salgado, J. M. Vidal-Taboada, and J. Saura, "C/EBP $\beta$ and C/EBP $\delta$ transcription factors: basic biology and roles in the CNS," Progress in Neurobiology, vol. 132, pp. 1-33, 2015.

[20] E. Acaz-Fonseca, M. Avila-Rodriguez, L. M. Garcia-Segura, and G. E. Barreto, "Regulation of astroglia by gonadal steroid hormones under physiological and pathological conditions," Progress in Neurobiology, vol. 144, pp. 5-26, 2016.

[21] L. H. Sun, F. Q. Yang, C. B. Zhang et al., "Overexpression of paxillin correlates with tumor progression and predicts poor survival in glioblastoma," CNS Neuroscience \& Therapeutics, 2016.

[22] T.-D. Leng, M.-H. Li, J.-F. Shen et al., "Suppression of TRPM7 inhibits proliferation, migration, and invasion of malignant human glioma cells," CNS Neuroscience \& Therapeutics, vol. 21, no. 3, pp. 252-261, 2015.

[23] Y.-L. Yao, J. Ma, P. Wang et al., "miR-101 acts as a tumor suppressor by targeting Kruppel-like factor 6 in glioblastoma stem cells," CNS Neuroscience \& Therapeutics, vol. 21, no. 1, pp. 40-51, 2015.

[24] D. M. Liu, H. J. Wang, B. Han, X. Q. Meng, M. H. Chen, and D. B. Yang, "CAMKK2, Regulated by promoter methylation, is a prognostic marker in diffuse gliomas," CNS Neuroscience \& Therapeutics, vol. 22, no. 6, pp. 518-524, 2016.

[25] A. C. Ferreira, S. Dá Mesquita, J. C. Sousa et al., "From the periphery to the brain: lipocalin-2, a friend or foe?" Progress in Neurobiology, vol. 131, pp. 120-136, 2015.

[26] S. L. Hollins and M. J. Cairns, "MicroRNA: small RNA mediators of the brains genomic response to environmental stress," Progress in Neurobiology, vol. 143, pp. 61-81, 2016.

[27] P. Saftig and S. F. Lichtenthaler, "The alpha secretase ADAM10: a metalloprotease with multiple functions in the brain," Progress in Neurobiology, vol. 135, pp. 1-20, 2015. 
[28] L.-J. Yang, C.-F. Zhou, and Z.-X. Lin, “Temozolomide and radiotherapy for newly diagnosed glioblastoma multiforme: a systematic review," Cancer Investigation, vol. 32, no. 2, pp. 3136, 2014.

[29] M. F. R. McAleer and P. D. Brown, "Therapeutic management of gliosarcoma in the temozolomide era," CNS oncology, vol. 4, no. 3, pp. 171-178, 2015.

[30] M. E. Hegi, A.-C. Diserens, T. Gorlia et al., "MGMT gene silencing and benefit from temozolomide in glioblastoma," New England Journal of Medicine, vol. 352, no. 10, pp. 997-1003, 2005.

[31] J. G. Pérez-Larraya, F. Ducray, O. Chinot et al., “Temozolomide in elderly patients with newly diagnosed glioblastoma and poor performance status: an ANOCEF phase II trial," Journal of Clinical Oncology, vol. 29, no. 22, pp. 3050-3055, 2011.

[32] A. A. Brandes, E. Franceschi, A. Tosoni et al., "MGMT promoter methylation status can predict the incidence and outcome of pseudoprogression after concomitant radiochemotherapy in newly diagnosed glioblastoma patients," Journal of Clinical Oncology, vol. 26, no. 13, pp. 2192-2197, 2008.

[33] P. S. Reddy, S. Umesh, B. Thota et al., "PBEF1/NAmPRTase/Visfatin: a potential malignant astrocytoma/glioblastoma serum marker with prognostic value," Cancer Biology \& Therapy, vol. 7, no. 5, pp. 663-668, 2008.

[34] P. Yang, L. Zhang, Q.-J. Shi et al., "Nicotinamide phosphoribosyltransferase inhibitor APO866 induces C6 glioblastoma cell death via autophagy," Die Pharmazie, vol. 70, no. 10, pp. 650655,2015

[35] K. Tateishi, H. Wakimoto, A. J. Iafrate et al., "Extreme vulnerability of IDH1 mutant cancers to NAD+ depletion," Cancer Cell, vol. 28, no. 6, pp. 773-784, 2015.

[36] A.-K. Elf, P. Bernhardt, T. Hofving et al., "NAMPT inhibitor GMX1778 enhances the efficacy of ${ }^{177}$ Lu-DOTATATE treatment of neuroendocrine tumors," Journal of Nuclear Medicine, 2016.

[37] J. Feng, P.-F. Yan, H.-Y. Zhao, F.-C. Zhang, W.-H. Zhao, and M. Feng, "SIRT6 suppresses glioma cell growth via induction of apoptosis, inhibition of oxidative stress and suppression of JAK2/STAT3 signaling pathway activation," Oncology Reports, vol. 35, no. 3, pp. 1395-1402, 2016.

[38] P. Wang, T.-Y. Xu, Y.-F. Guan, D.-F. Su, G.-R. Fan, and C.Y. Miao, "Perivascular adipose tissue-derived visfatin is a vascular smooth muscle cell growth factor: role of nicotinamide mononucleotide," Cardiovascular Research, vol. 81, no. 2, pp. 370-380, 2009.

[39] C. R. Oliva, D. R. Moellering, G. Y. Gillespie, and C. E. Griguer, "Acquisition of chemoresistance in gliomas is associated with increased mitochondrial coupling and decreased ROS production," PLOS ONE, vol. 6, no. 9, Article ID e24665, 2011.

[40] E. F. Wagner and Á. R. Nebreda, "Signal integration by JNK and p38 MAPK pathways in cancer development," Nature Reviews Cancer, vol. 9, no. 8, pp. 537-549, 2009.

[41] A. Chiarugi, C. Dölle, R. Felici, and M. Ziegler, "The NAD metabolome-a key determinant of cancer cell biology," Nature Reviews Cancer, vol. 12, no. 11, pp. 741-752, 2012.

[42] M. Watson, A. Roulston, L. Bélec et al., "The small molecule GMX1778 is a potent inhibitor of NAD+ biosynthesis: strategy for enhanced therapy in nicotinic acid phosphoribosyltransferase 1-deficient tumors," Molecular and Cellular Biology, vol. 29, no. 21, pp. 5872-5888, 2009.

[43] A. Cagnetta, I. Caffa, C. Acharya et al., "APO866 increases antitumor activity of cyclosporin-a by inducing mitochondrial and endoplasmic reticulum stress in leukemia cells," Clinical Cancer Research, vol. 21, no. 17, pp. 3934-3945, 2015.
[44] G. Zoppoli, M. Cea, D. Soncini et al., "Potent synergistic interaction between the Nampt inhibitor APO866 and the apoptosis activator TRAIL in human leukemia cells," Experimental Hematology, vol. 38, no. 11, pp. 979-988, 2010.

[45] O. Abu Aboud, C.-H. Chen, W. Senapedis, E. Baloglu, C. Argueta, and R. H. Weiss, "Dual and specific inhibition of NAMPT and PAK4 By KPT-9274 decreases kidney cancer growth," Molecular Cancer Therapeutics, vol. 15, no. 9, pp. 21192129, 2016.

[46] Z. Moore, G. Chakrabarti, X. Luo et al., "NAMPT inhibition sensitizes pancreatic adenocarcinoma cells to tumor-selective, PAR-independent metabolic catastrophe and cell death induced by $\beta$-lapachone," Cell Death \& Disease, vol. 6, no. 1, Article ID e1599, 2015.

[47] M. Chan, M. Gravel, A. Bramoullé et al., "Synergy between the NAMPT inhibitor GMX1777(8) and pemetrexed in nonsmall cell lung cancer cells is mediated by PARP activation and enhanced NAD consumption," Cancer Research, vol. 74, no. 21, pp. 5948-5954, 2014.

[48] I. Bajrami, A. Kigozi, A. Van Weverwijk et al., "Synthetic lethality of PARP and NAMPT inhibition in triple-negative breast cancer cells," EMBO Molecular Medicine, vol. 4, no. 10, pp. 1087-1096, 2012.

[49] D. Villela, D. Schlesinger, C. K. Suemoto, L. T. Grinberg, and C. Rosenberg, "A microdeletion in Alzheimer's disease disrupts NAMPT gene," Journal of Genetics, vol. 93, no. 2, pp. 535-537, 2014.

[50] D. Ghosh, K. R. Levault, and G. J. Brewer, "Relative importance of redox buffers GSH and $\mathrm{NAD}(\mathrm{P}) \mathrm{H}$ in age-related neurodegeneration and Alzheimer disease-like mouse neurons," Aging Cell, vol. 13, no. 4, pp. 631-640, 2014.

[51] J. A. Santiago, A. M. Littlefield, and J. A. Potashkin, "Integrative transcriptomic meta-analysis of Parkinson's disease and depression identifies NAMPT as a potential blood biomarker for de novo Parkinson's disease," Scientific Reports, vol. 6, article 34579, 2016.

[52] L. R. Stein, D. F. Wozniak, J. T. Dearborn et al., "Expression of Nampt in hippocampal and cortical excitatory neurons is critical for cognitive function," The Journal of Neuroscience, vol. 34, no. 17, pp. 5800-5815, 2014.

[53] E. Esposito, D. Impellizzeri, E. Mazzon et al., "The NAMPT inhibitor FK866 reverts the damage in spinal cord injury," Journal of Neuroinflammation, vol. 9, article 66, 2012.

[54] B. A. Harlan, M. Pehar, D. R. Sharma, G. Beeson, C. C. Beeson, and M. R. Vargas, "Enhancing $\mathrm{NAD}^{+}$salvage pathway reverts the toxicity of primary astrocytes expressing amyotrophic lateral sclerosis-linked mutant superoxide dismutase 1 (SOD1)," Journal of Biological Chemistry, vol. 291, no. 20, pp. 1083610846, 2016.

[55] M. Di Stefano, I. Nascimento-Ferreira, G. Orsomando et al., "A rise in NAD precursor nicotinamide mononucleotide (NMN) after injury promotes axon degeneration," Cell Death and Differentiation, vol. 22, no. 5, pp. 731-742, 2015.

[56] D. E. Clark, B. Waszkowycz, M. Wong et al., "Application of virtual screening to the discovery of novel nicotinamide phosphoribosyltransferase (NAMPT) inhibitors with potential for the treatment of cancer and axonopathies," Bioorganic \& Medicinal Chemistry Letters, vol. 26, no. 12, pp. 2920-2926, 2016.

[57] P. Wang and C.-Y. Miao, "NAMPT as a therapeutic target against stroke," Trends in Pharmacological Sciences, vol. 36, no. 12, pp. 891-905, 2015. 
[58] P. Wang, T.-Y. Xu, Y.-F. Guan et al., "Nicotinamide phosphoribosyltransferase protects against ischemic stroke through SIRT1-dependent adenosine monophosphate-activated kinase pathway," Annals of Neurology, vol. 69, no. 2, pp. 360-374, 2011.

[59] P. Wang, Y.-F. Guan, H. Du, Q.-W. Zhai, D.-F. Su, and C.-Y. Miao, "Induction of autophagy contributes to the neuroprotection of nicotinamide phosphoribosyltransferase in cerebral ischemia," Autophagy, vol. 8, no. 1, pp. 77-87, 2012.

[60] P. Wang, H. Du, C. Zhou et al., "Intracellular NAMPT$\mathrm{NAD}^{+}$-SIRT1 cascade improves post-ischaemic vascular repair by modulating Notch signalling in endothelial progenitors," Cardiovascular Research, vol. 104, no. 3, pp. 477-488, 2014.

[61] Y. Zhao, Y.-F. Guan, X.-M. Zhou et al., "Regenerative neurogenesis after ischemic stroke promoted by nicotinamide phosphoribosyltransferase-nicotinamide adenine dinucleotide cascade," Stroke, vol. 46, no. 7, pp. 1966-1974, 2015.

[62] R. Van Horssen, M. Willemse, A. Haeger et al., "Intracellular $\mathrm{NAD}(\mathrm{H})$ levels control motility and invasion of glioma cells," Cellular and Molecular Life Sciences, vol. 70, no. 12, pp. 21752190, 2013.

[63] L.-Y. Zhang, L.-Y. Liu, L.-L. Qie et al., "Anti-proliferation effect of APO866 on C6 glioblastoma cells by inhibiting nicotinamide phosphoribosyltransferase," European Journal of Pharmacology, vol. 674, no. 2-3, pp. 163-170, 2012.

[64] A.-J. Liu, S.-H. Wang, K.-C. Chen et al., "Evodiamine, a plant alkaloid, induces calcium/JNK-mediated autophagy and calcium/mitochondria-mediated apoptosis in human glioblastoma cells," Chemico-Biological Interactions, vol. 205, no. 1, pp. 20-28, 2013.

[65] C. Trejo-Solís, D. Jimenez-Farfan, S. Rodriguez-Enriquez et al., "Copper compound induces autophagy and apoptosis of glioma cells by reactive oxygen species and JNK activation," BMC Cancer, vol. 12, article 156, 2012.

[66] M. T. Tomicic, R. Meise, D. Aasland et al., "Apoptosis induced by temozolomide and nimustine in glioblastoma cells is supported by $\mathrm{JNK} / \mathrm{c}$-Jun-mediated induction of the $\mathrm{BH} 3$-only protein BIM," Oncotarget, vol. 6, no. 32, pp. 33755-33768, 2015. 


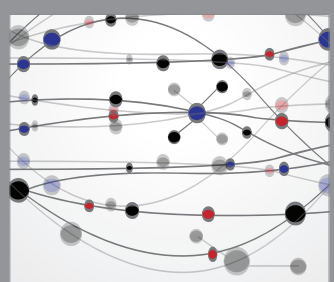

The Scientific World Journal
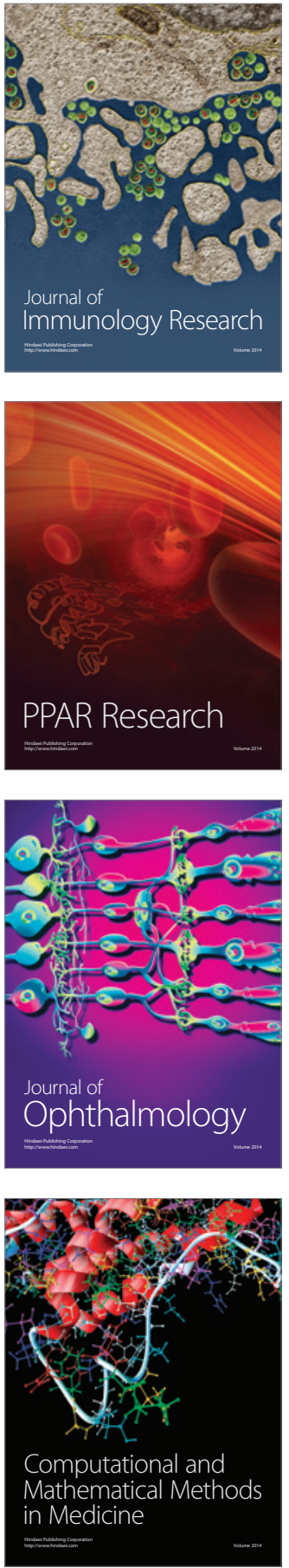

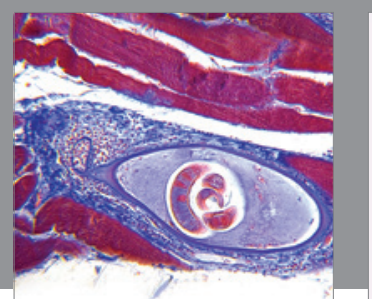

Gastroenterology Research and Practice

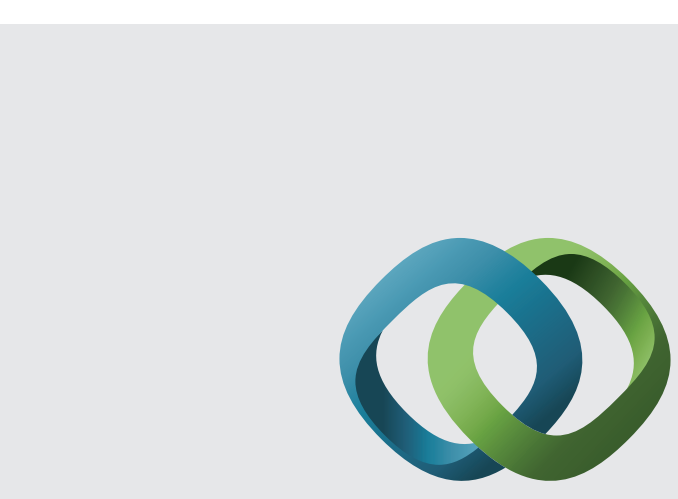

\section{Hindawi}

Submit your manuscripts at

http://www.hindawi.com
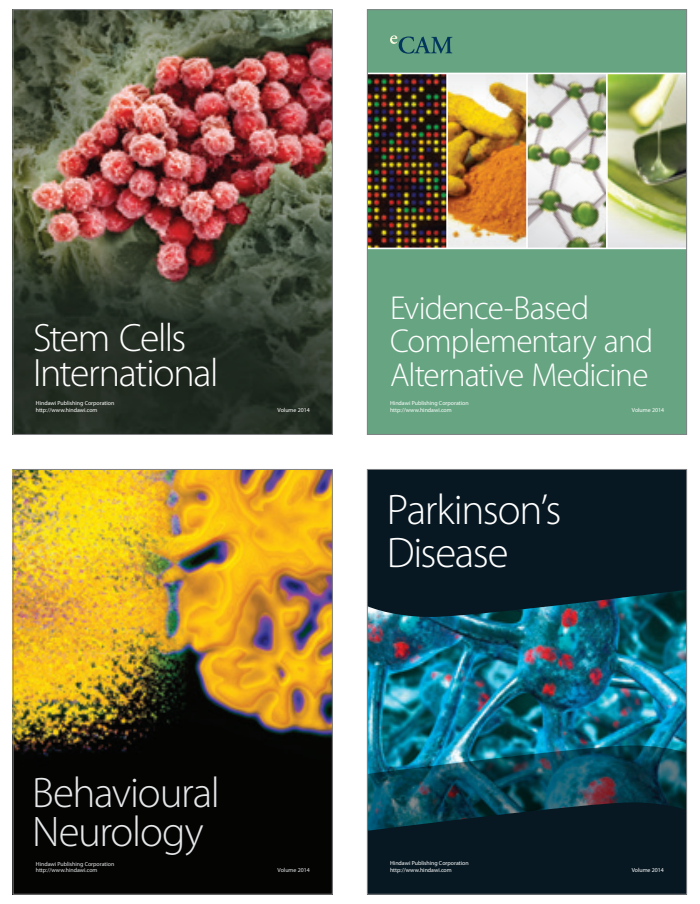
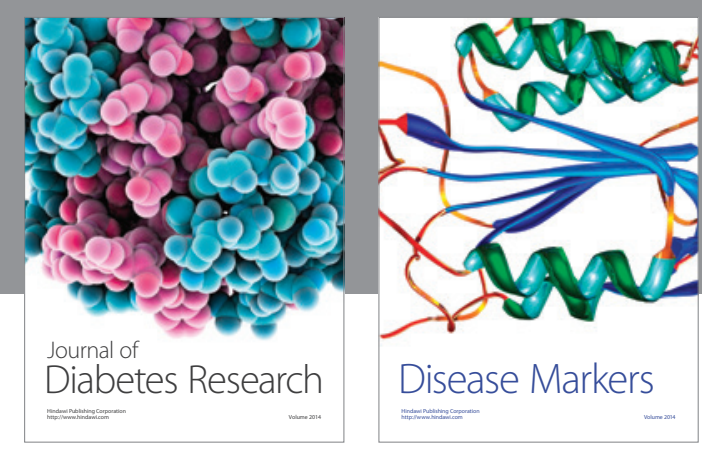

Disease Markers
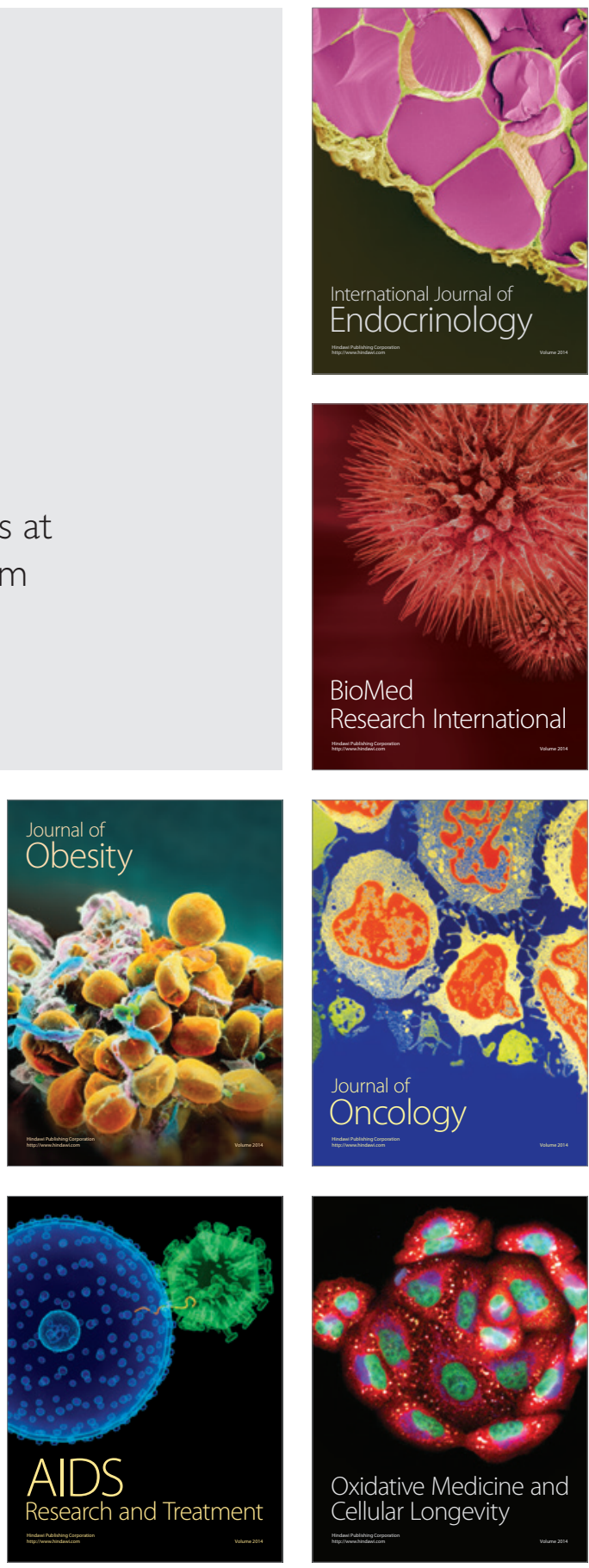